\title{
Choroidal and Ciliary Body Melanoma pT3a TNM Finding v8
}

National Cancer Institute

\section{Source}

National Cancer Institute. Choroidal and Ciliary Body Melanoma pT3a TNM Finding v8. NCI Thesaurus. Code C140642.

Choroidal and ciliary body melanoma, tumor size category 3 without ciliary body involvement and extraocular extension. (from AJCC 8th Ed.) 